\title{
A Study on the Impact of Using Multimedia to Improve the Quality of English Language Teaching
}

\author{
Abbas Pourhosein Gilakjani \\ Lahijan Branch, Islamic Azad University, Lahijan, Iran \\ Email: a_p_g48@yahoo.com
}

\begin{abstract}
One of the most important uses of technology is that it makes it easy for instructors to incorporate multimedia into their teaching. There are different multimedia tools. Three of the most popular ones are visual, auditory, and kinaesthetic in which students take in information. Some students are visual learners, while others are auditory or kinaesthetic learners. While students use all of their senses to take in information, they seem to have preferences in how they learn best. In order to help students learn, teachers need to teach as many of these preferences as possible. Therefore, teachers can incorporate these multimedia tools in their curriculum activities so that students are able to succeed in their classes. This study is an analysis of multimedia tools for Iranian EFL students. Over 100 students complete a questionnaire to determine if their multimedia tools are auditory, visual, or kinaesthetic. The purpose of this study is to increase faculty awareness and understanding of the impact of multimedia tools on the teaching process. A review of the literature along with analysis of the data will determine how multimedia tools affect the teaching process.
\end{abstract}

Index Terms - multimedia, auditory, visual, kinaesthetic, effective teaching

\section{INTRODUCTION}

Multimedia provides a complex multi-sensory experience in exploring our world through the presentation of information through text, graphics, images, audio and video, and there is evidence to suggest that a mixture of words and pictures increases the likelihood that people can integrate a large amount of information (Mayer, 2001). Advantages of multimedia design compared to using a single medium might result from the ability to choose among media to present well-structured information (Larkin \& Simon, 1987), using more than one representation to improve memory (Penney, 1989), encouraging active processing (Ainsworth, 1999), and presenting more information at once (Sweller, 1999). Students learn best by seeing the value and importance of the information presented in the classroom. If the students are not interested in the material presented, they will not learn it. In order to achieve the ultimate goal of student learning it is important to use a combination of teaching methods and to make the classroom environment as stimulating and interactive as possible. Students learn in many different ways. Some students are visual learners, while others are auditory or kinaesthetic learners. Visual learners learn visually by means of charts, graphs, and pictures. Auditory learners learn by listening to lectures and reading. Kinaesthetic learners learn by doing. Students can prefer one, two, or three learning styles.

Because of these different learning styles, it is important for teachers to incorporate in their curriculum activities related to each of these learning styles so that all students are able to succeed in their classes. While we use all of our senses to take in information, we each seem to have preferences in how we learn best. In order to help all students learn, we need to teach to as many of these preferences as possible (Cuaresma, 2008). When we think about a typical university course, it is rare to find all three of these approaches to learning incorporated into a class. While it may seem impossible to do this, it can be done through thoughtful planning and preparation. It does force us to conceptualize the class differently — with a focus on the variety of ways in which students learn. The various inventories on learning styles allow teachers to gain insight into which areas they can use further development in and which are already well developed. It is dangerous to apply only one learning theory to teaching. If teachers do this, they are not allowing students to develop their skills in other learning styles that are applicable to real-life situations. In this paper, the researchers discuss the definition of multimedia, multimedia and learning, analysis towards visual, auditory, and kinaesthetic learning styles, the usefulness of multimedia-based education, teachers and their roles in multimedia environment, and situation of multimedia tools in Iran.

\section{The Definition of Multimedia}

Multimedia may be defined in multiple ways, depending upon one's perspective. Typical definitions include the following:

1) Multimedia is the "use of multiple forms of media in a presentation" (Schwartz \& Beichner, 1999, p. 8). 
2) Multimedia is "information in the form of graphics, audio, video, or movies. A multimedia document contains a media element other than plain text” (Greenlaw \& Hepp, 1999, p. 44).

3) Multimedia comprises a computer program that includes "text along with at least one of the following: audio or sophisticated sound, music, video, photographs, 3-D graphics, animation, or high-resolution graphics” (Maddux, Johnson, \& Willis, 2001, p. 253).

\section{Multimedia AND LEARNING}

Multimedia has been successfully applied to many courses in order to provide a wide variety of learning styles or modalities. Learning styles are defined as characteristic cognitive, affective, and physiological behaviours that serve as relatively stable indicators of how learners perceive, interact with, and respond to the learning environment. Learners are more comfortable learning in an environment which reflects their predominant learning style (Sankey, 2006). Learners have a preferred learning modality, namely, visual, aural, read/write or kinaesthetic, while many learners are multimodal (use a combination of these modalities). Multimedia can be used to develop a more inclusive curriculum that appeals to visual, aural and kinaesthetic learners and overcome differences in student performance that may result from different learning styles. Presenting material in a variety of modes has been used to encourage students to develop a more versatile approach to learning (Morrison, Sweeney, \& Heffernan, 2003).

Moving from the book to the computer is the opportunity for greater interactivity and novel ways to think about a learning activity. Technology provides more ways to represent concepts through different media formats. Such advances in technology ask for pedagogical enquiries to confirm the usefulness of such new activities in facilitating learning. Learners who have access to multiple representations enhance their comprehension, learning, memory, communication and inference (Rogers \& Scaife, 1996). Kozma (1991) argues that learners will benefit more if the instructional methods provide, perform or model cognitive operations that are important to the task and the situation. Learners will also benefit more if they can perform or provide for themselves the operations provided by these representational media (Kozma, 1991). Providing the learner with a sound structure and content is more important than providing them with interactivity and animation afforded by new media. Comprehension and learning require a sound content and structure of instructional material, and not new media or types of representation. The combination of text and image is effective when the information provided is complementary and adapted to each presentation. Making connections from multiple representations depend not only on the presentation mode and the construction of the interrelations between the multimodal items but also on the characteristics of the task (Dubois \& Vial, 2000).

\section{ANAlysis towards Multimedia ToOls: Visual, Auditory, AND KinESTHETiC}

According to Dunn and Dunn (1978), only 20-30\% of school age children appear to be auditory learners, $40 \%$ are visual learners, and 30-40\% are tactile/kinaesthetic or visual/tactile learners. Barbe and Milone (1981) stated that for grade school children the most frequent modality strengths are visual (30\%) or mixed (30\%), followed by auditory (25\%), and then by kinaesthetic (15\%). Barbe and Milone (1981) stated that primary grade children learn better via auditory (verbal) means and are least well developed kinaesthetically, however between kindergarten and sixth grade a modality shift occurs and vision becomes the dominant modality and kinaesthesia overtakes audition (Barbe \& Milone, 1981). Barbe and Milone (1981) also wrote that adults are more likely to have mixed modality strengths than children. In addition, it has been found that modality strengths differ with regard to achievement level. Price, Dunn, and Sanders (1980) found that very young children are the most tactile/kinesthetic, that there is a gradual development of visual strengths through the elementary grades, and that only in fifth or sixth grade can most youngsters learn and retain information through the auditory sense. Carbo (1983), investigating the perceptual styles of readers, found that good readers prefer to learn through their visual and auditory senses, while poor readers have a stronger preference for tactile and kinesthetic learning.

Previous studies into the learning styles of EFL students have generally reported that they favor Kinesthetic and Tactile styles, and disfavor Group styles. Reid (1987) reports that Chinese university students ( $=90)$ studying in the USA favored Kinesthetic and Tactile styles, and disfavored Group styles. Melton (1990) found that Chinese (PRC) university students $(\mathrm{N}=331)$ favored Kinesthetic, Tactile and Individual styles, and disfavored Group styles. Jones (1997) states that his Chinese (Taiwan) university students $(\mathrm{N}=81)$ favored Kinesthetic and Tactile styles, and disfavored Individual styles. The Singapore university students in Chu, Kitchen and Chew's 1997 study (N = 318) favored Kinesthetic and Tactile styles, and did not disfavor any styles. Two empirical studies that investigated nonChinese EFL students based on Reid's typology are Rossi-Le (1995) and Hyland (1993). Rossi-Le surveyed adult L2 immigrants in the US. They favored Kinesthetic and Tactile styles and did not disfavor any styles. Hyland's Japanese learners favored Auditory and Tactile styles, and disfavored Visual and Group styles (1993). Hyland also reports that senior students favored kinesthetic styles.

In a classroom environment students with limited English proficiency rely heavily on visual clues for the comprehension and acquisition of learning content (Olmeda, 2003). In a study on perceptual learning styles and achievement in a university level foreign language course, Renou (2004) found out that there is no significant difference between the predominant learning style groups and course graders. In other words, whether one is a visual, auditory, or 
kinesthetic learner, this has no significant bearing on achievement in school as measured by grades. In their research, Kia, Alipour, and Ghaderi (2001) found that among students in Payame Noor University in Iran, those with visual learning style have the greatest academic achievement. Peacock (2001) has examined the learning style preferences of EFL and ESL students. The results of these studies show that students prefer kinesthetic learning styles above others, whereas the teaching methods mostly suit auditory learners.

\section{The Usefulness OF Multimedia InstruCtion}

Multimedia-based education when used only in certain situations would maximize the returns. Using it in every circumstance would not give the desired results and also require huge amounts in infrastructure costs. We will discuss three main situations when using multimedia instruction would be appropriate.

\section{A. When the Students Have Low Prior Domain Knowledge or Spatial Learning Aptitude.}

When multimedia is used with students who have low prior domain knowledge or spatial aptitude, it helps the students in developing mental models and connect to the new knowledge domain. They are better able to visualize the activities in the knowledge domain and learn from them. On the other hand a student with high prior domain knowledge or high spatial aptitude would be able to create mental models of the knowledge domain without any external help and not gain anything from the use of multimedia (Mayer \& Moreno, 2003).

\section{B. When Students Have Low Motivation.}

When dealing with students with low learning motivation, it is very important to keep them interested in learning. Interesting lessons would keep the students interested and enable them to do their own self-directed learning and research. Use of pictures, animations and sounds can help in keeping the students interested in learning about a new domain. The interactivity generated by the use of multimedia instruction would also help in motivating the students towards learning. On the other hand highly motivated students might not need these audio-visual aids and be able to understand the instructions given in text format itself (Tan \& Leong, 2003).

\section{When Effectively Designed Multimedia Content is Available.}

This is indeed the most difficult aspect to deal with in the use of multimedia-based instruction. Unless we have properly designed multimedia content, there is no point in using it. Mayer and Mareno (2002) suggest few key design principles in the creation multimedia instruction. They are as follows:

1) Multimedia Representation Principle: It is better to present an explanation in words and text rather than text alone.

2) Contiguity Principle: Present the words and text contiguously rather than separately.

3) Split Attention Principle: When giving explanation, present words as auditory narration rather than as visual on screen text.

4) Coherence Principle: Wherever possible, it is better to use fewer words and pictures than using too many of them.

\section{TEACHERS AND THEIR Roles IN MUltimedia EnVIRONMENT}

There is an increasing awareness amongst educationalists, researchers and administrators that the introduction of the multimedia into educational institutions calls for a change in learning and teaching patterns. For example, $73 \%$ of the experts polled for the Delphi Study (Vollstädt - forthcoming publication) conducted for the German Federal Ministry of Education and Research over a period of two years and culminating in a symposium in February 2002, believe that the multimedia will lead to a major change in the culture of learning and teaching. They believe that teachers have some important roles in multimedia. They are as follows:

\section{A. Facilitator and Guide}

As facilitators, teachers must know more than they would as directive givers of information. Facilitators must be aware of a variety of materials available for improving students' language skill, not just one or two texts. The language textbook is no longer the sole source of information. Multimedia programs offer sound and vision, showing how native speakers interact; electronic dictionaries and encyclopedias are available for instant reference; online newspapers provide up-to-date information on current affairs in the countries of the target language; (official) websites offer background information on policy, tourism, political views. Teachers need to know how to teach learners to use all this material effectively. As facilitators, teachers have to be flexible, responding to the needs that students have, not just what has been set up ahead of time based on a curriculum developer's idea of who will be in the classroom (Vollstädt, 2002).

\section{B. Integrator}

Teachers must not only know and understand the functions of different media available in a media-rich environment, they should also know when best to deploy them. In the construction of projects with their learners, they need to guide learners in the use of word-processing, graphics and presentation programs. Integration of audio-visual elements will 
bring home to learners the fact that the foreign language environment of the target language is as vibrant and multifaceted as the society in which they live (Vollstädt, 2002).

\section{Researcher}

Teachers need to know how and where they can access information for their own and for their learners' use. Knowledge and competent use of search engines and reliable information sources are essential. For those concerned with mainstream education, the propriety and reliability of information sources must figure as one of the main criteria for the selection of background material. Familiarity with the use of electronic tools for language analysis will enable teachers to develop their own linguistic and professional competence and increase their confidence in the use of the language (Vollstädt, 2002).

\section{Designer}

In order to organize successful learning situation, teachers need to learn how to put together tasks and materials to guide their learners to successful execution and conclusion of their projects. The design of learning situation is much more complex, requiring higher order skills involving researching and evaluating source materials, setting overall aims and objectives and breaking down tasks into meaningful and manageable sequences. Encouragement, help and advice is needed in terms of examples of good practice which may be emulated or serve as sources of inspiration for similar undertakings. If this new role of language teachers is accepted and encouraged by educational authorities, the implications in terms of duties and responsibilities need to be considered (Vollstädt, 2002).

\section{E. Collaborator}

Collaboration with colleagues will lighten the burden and make the efforts more fruitful and rewarding. Obviously, co-operation within a specific teaching institution will prove more efficient, producing tailor-made responses to the local situation, but the new media provide possibilities for exchange between institutions and beyond (national) borders. Teachers of the less widely taught and used languages could well profit from such internet exchanges, helping them to overcome the sense of isolation many experience in their teaching situation (Vollstädt, 2002).

\section{Visual, AUDITORY, AND KINESTHETIC LEARNING STYLES AMONG IRANIAN LEARNERS}

In order to understand the learning preferences of Iranian EFL learners, VAK learning style model was used (Chislett \& Chapman, 2005). The VAK learning styles model suggests that most people can be divided into one of three preferred styles of learning. These three styles are as follows, (and there is no right or wrong learning style): Someone with a visual learning style has a preference for seen or observed things, including pictures, diagrams, demonstrations, displays, handouts, films, flip-chart, etc. Someone with an auditory learning style has a preference for the transfer of information through listening: to the spoken word, of self or others, of sounds and noises. Someone with a kinaesthetic learning style has a preference for physical experience - touching, feeling, holding, doing, practical hands-on experiences. People commonly have a main preferred learning style, but this will be part of a blend of all three. Some people have a very strong preference; other people have a more even mixture of two or less commonly, three styles. There is no right or wrong learning style. The point is that there are types of learning that are right for our own preferred learning style.

The participants of this study were 100 students of English majoring in translation. They were 35 male and 65 female students between 21 and 25 years of age. They were studying in English Translation at the Islamic Azad University of Lahijan, Iran. Thirty questions with three alternatives were distributed to students. Through the processes of test administration, it was indicated that about $55 \%$ of the students preferred visual learning style, $35 \%$ of the students preferred auditory learning style, and only $10 \%$ of the students preferred kinaesthetic style for their learning. Based on the above finding, it can be concluded that the prevalent learning style among EFL students in Islamic Azad University of Lahijan, Iran was visual one and students with this type of learning style had the greatest academic achievement in their educational major. It is the responsibility of the instructor and the student to be aware of learning style preferences to improve their teaching and learning. As instructors, we need to assess and understand how to reach all students by understanding how to present information in multiple modes. We can help students more effectively both in and out of the classroom, if we are aware of their learning style and can assist them in determining their preferences. As a student, it is vital to be self-aware of preferences to adjust study techniques to best fit each individual, even when the information and instruction provided does not match the preferred style.

\section{CONCLUSION}

Multimedia instruction creates the opportunity for learners to improve their learning effectively. Only under the background of effective education we can use advanced educational theory and fulfill the target of English teaching by utilizing modern education technology reasonably. We must understand teachers' use of multimedia tools and relate this to the university context. It is very important to understand and explore each individual's learning style. Analyzing one's own particular learning style can be very helpful and beneficial to the student by aiding them in becoming more focused on an attentive learner, which ultimately will increase educational success. Discovering this learning style will 
allow the student to determine his or her own personal strengths and weaknesses and learn from them. Teachers can incorporate learning styles into their classroom by identifying the learning styles of each of their students, matching teaching style to learning style for difficult tasks, strengthening weaker learning styles through easier tasks and drill, and teaching students, learning-style selection strategies It is important for students to have multiple learning opportunities and "learning style-shift" and teachers should achieve a match between teaching strategies and the students' unique learning styles. Accommodating teaching to learning styles improves students' overall learning results, increases both motivation and efficiency and enables a positive attitude towards the language being learned. Teachers should have the time to develop and reinforce their expertise as well as the opportunity within the university context to spread their information, ideas, findings, and experience. Teachers should know the needs of their students as well as their necessary requirements - this is vital if multimedia are to be used in universities effectively. Multimedia that's effective in learning and teaching doesn't simply consist of using multiple media together, but combining media mindfully in ways that capitalize on the characteristics of each individual medium and extend the learning and teaching experiences. Teachers should first determine what outcomes they are trying to achieve and then select elements well suited for these outcomes. Then they need to make sure that the multimedia elements are designed well and work well together. Determining when to use multimedia and designing good multimedia require real consideration and benefits from a team of people with instructional design, graphic arts, information architecture, and usability skills. Although multimedia offers teachers enormous opportunities for making learning and teaching environments meaningful and effective, multimedia by itself does not assure a good learning and teaching environment. Multimedia cannot provide the answer to the problems of resourcing, motivation, and standards in education. Technology is not a proxy for time and money - it needs to work effectively. The purpose of using multimedia tools in universities is to find the best ways for both students to learn effectively and teachers to teach efficiently. Depending on the type of course and class size, some of the following teaching strategies can be used by teachers in a class in order to encourage the learning processes:

1) Provide challenging and novel problems to students

2) Use examples that require analysis and synthesis

3) Require application of information and concepts

4) Encourage questions and discussion

5) Assign collaborative group projects

6) Combine visual, auditory, tactile, and kinesthetic techniques

7) Assign open-ended activities encouraging creativity

8) Encourage use of technology and alternative multimedia

\section{ACKNOWLEDGEMENTS}

I thank Seyedeh Masoumeh Ahmadi, Alizadeh, Khazaei, and Babaei for their extensive and insightful discussions.

\section{ApPendix VAK LEARning Styles SElf-Assessment Questionnaire (ChisleTt \& Chapman, 2005)}

Circle or tick the answer that most represents how you generally behave.

1. When I operate new equipment I generally:
a) read the instructions first
b) listen to an explanation from someone who has used it before
c) go ahead and have a go, I can figure it out as I use it

\section{When I need directions for travelling I usually:}
a) look at a map
b) ask for spoken directions
c) follow my nose and maybe use a compass

\section{When I cook a new dish, I like to:}
a) follow a written recipe
b) call a friend for an explanation

c) follow my instincts, testing as I cook

4. If I am teaching someone something new, I tend to:
a) write instructions down for them
b) give them a verbal explanation
c) demonstrate first and then let them have a go

\section{I tend to say:}
a) watch how I do it
b) listen to me explain

6. During my free time I most enjoy:

a) going to museums and galleries

c) playing sport or doing DIY

7. When I go shopping for clothes, I tend to:

a) imagine what they would look like on

c) try them on and test them out

\section{When I am choosing a holiday I usually:}
a) read lots of brochures
c) imagine what it would be like to be there

9. If I was buying a new car, I would:

c) you have a go

b) listening to music and talking to my friends

b) discuss them with the shop staff

b) listen to recommendations from friends 

a) read reviews in newspapers and magazines
b) discuss what I need with my friends

c) test-drive lots of different types

10. When I am learning a new skill, I am most comfortable:

a) watching what the teacher is doing

b) talking through with the teacher exactly what I'm supposed to do

c) giving it a try myself and work it out as I go

11. If I am choosing food off a menu, I tend to:
a) imagine what the food will look like
b) talk through the options in my head or with my partner
c) imagine what the food will taste like

12. When I listen to a band, I can't help:
a) watching the band members and other people in the audience
b) listening to the lyrics and the beats
c) moving in time with the music

13. When I concentrate, I most often:
a) focus on the words or the pictures in front of me
b) discuss the problem and the possible solutions in my head
c) move around a lot, fiddle with pens and pencils and touch things

14. I choose household furnishings because I like:
a) their colours and how they look
c) their textures and what it feels like to touch them
b) the descriptions the sales-people give me

15. My first memory is of:
a) looking at something

16. When I am anxious, I:
a) visualise the worst-case scenarios
c) can't sit still, fiddle and move around constantly

17. I feel especially connected to other people because of:
a) how they look
b) what they say to me
c) how they make me feel

18. When I have to revise for an exam, I generally:
a) write lots of revision notes and diagrams
b) talk over my notes, alone or with other people
c) imagine making the movement or creating the formula

19. If I am explaining to someone I tend to:
a) show them what I mean
b) explain to them in different ways until they understand
c) encourage them to try and talk them through my idea as they do it

20. I really love:
a) watching films, photography, looking at art or people watching
b) listening to music, the radio or talking to friends
c) taking part in sporting activities, eating fine foods and wines or dancing

21. Most of my free time is spent:
a) watching television
b) talking to friends
c) doing physical activity or making things

22. When I first contact a new person, I usually:
a) arrange a face to face meeting
b) talk to them on the telephone
c) try to get together whilst doing something else, such as an activity or a meal

23. I first notice how people:
a) look and dress
b) sound and speak
c) stand and move

24. If I am angry, I tend to:

a) keep replaying in my mind what it is that has upset me

b) raise my voice and tell people how I feel

c) stamp about, slam doors and physically demonstrate my anger

25. I find it easiest to remember:
a) faces
b) names
c) things I have done

26. I think that you can tell if someone is lying if:
a) they avoid looking at you
b) their voices changes
c) they give me funny vibes

27. When I meet an old friend:
a) I say "it's great to see you!"
c) I give them a hug or a handshake

28. I remember things best by:

a) writing notes or keeping printed details b) I say "it's great to hear from you!" 
b) saying them aloud or repeating words and key points in my head

c) doing and practising the activity or imagining it being done

29. If I have to complain about faulty goods, I am most comfortable:
a) writing a letter
b) complaining over the phone

c) taking the item back to the store or posting it to head office

\section{I tend to say:}
a) I see what you mean
b) I hear what you are saying
c) I know how you feel
Good Luck

\section{REFERENCES}

[1] Ainsworth, S. E. (1999). A functional taxonomy of multiple representations. Computers and Education, 33, (2/3), 131-152.

[2] Barbe, W. B., \& Milone, M. N. (1981). What we know about modality strengths. Educational Leadership, 38, 5, 378-380.

[3] Carbo, M. (1983). Research in reading and learning style: Implications for exceptional children. Exceptional Childre,. 49, 486494.

[4] Chislet, V., \& Chapman, A. (2005). VAK learning styles self-test. In http://www.businessballs.com.vakleearningstylestest.htm.

[5] Chu, L., Kitchen, T., \& Chew, M. L. (1997). How do we learn best? In Preferences and strategies in learning and teaching styles at the National University of Singapore. Paper presented at Singapore Tertiary English Teachers Society/National Tsinghua University Joint Seminar, Hsin Chu, Taiwan. (Note: A modified version of this paper appears in Asian Journal of English Language Teaching, 9, 1-21.

[6] Cuaresma, j. (2008). Learning style preferences and academic performance of PHEM majors at the University of the Cordilleras. In Unpublished Undergraduate Thesis. University of the Cordilleras, Baguio City.

[7] Dubois, M., \& Vial, I. (2001). Multimedia design: the effects of relating multimodal information. Journal of Computer Assisted Learning, 16, 157-165.

[8] Dunn, R., \& Dunn, K. (1978). Teaching Students through Their Individual Learning Styles.” In A Practical Approach. Prentice Hall, Reston, VA., ISBN: 10: 0879098082, 1978: 336.

[9] Greenlaw, R., \& Eb. (1999). In-line/On-line. Fundamentals of the Internet and the World Wide Web. Boston: McGraw-Hill.

[10] Hong, T. L., \& Leong, P. (2003). Professional Development of ITE Teachers through Learning Circles. Teacher Education Institute, 2003.

[11] Hyland, K. (1993). Culture and learning: a study of the learning style preferences of Japanese students. RELC Journal, 24, 2 , 69-91.

[12] Jones, N. B. (1997). Applying learning styles research to improve writing instruction. Paper presented at RELC Seminar on Learners and Language Learning, Singapore.

[13] Kia, M., Alipou, A., \& Ghaderi, E. (2009). Study of learning styles on their roles in the academic Achievement of the students of Payame Noor University. In http://tojde.andolu.edu.tr/tojde 34/notes, Retrieved June 11, 2009.

[14] Kozma, R. B. (1991). Learning with media. Review of Educational Research, 61, 179-211.

[15] Larkin, J. H., \& Simon, H. A. (1987). Why a diagram is (sometimes) worth ten thousand words. Cognitive Science, 11, 1, 65.

[16] Maddux, C., Johnson, D., \& Willis, J. (2001). Learning with tomorrow's technologies. Educational Computer. Boston: Allyn and Bacon.

[17] Mayer, R., \& Moreno, R. (2003). Nine ways to reduce cognitive load in multimedia learning. Educational Psychologist, 38, 1, 43-52.

[18] Mayer, R. (2001). Multimedia Learning. Boston: Cambridge University Press.

[19] Mayer, R. E., \& Moreno, R. (2002). Aids to computer-based multimedia learning. Learning and Instruction, 12, $107-119$.

[20] Melton, C. D. (1990). Bridging the cultural gap: a study of Chinese students' learning style preferences. RELC Journal, 21, 1, $29-54$.

[21] Morrison, M., Sweeney, A., \& Hefferman, T. (2003). Learning styles of on-campus and off-campus marketing students: The challenge for marketing educators. In Journal of Marketing Education, 25, 3, 208-217.

[22] Olmedo, I. (2003). Language Mediation among Emerging Bilingual Children. Linguistics and Education, 14, 2, 143-16.

[23] Peacock, M. (2001). Match or mismatch? Learning styles and teaching styles in EFL. International journal of Applied Linguistics, 11, 1, 1-20.

[24] Penney, C. G. (1989). Modality effects and the structure of short-term verbal memory. Memory and Cognition, $17,4,398$.

[25] Price, G. E., Dunn, R., \& Sanders, W. (1980). Reading achievement and learning style characteristics. The Clearing House, 5, 223-226.

[26] Reid, J.M. (1987). The learning style preferences of ESL students. TESOL Quarterly, 21, 1, 87-111.

[27] Renou, J. (2004). A study of perceptual learning style and achievement in a university level foreign language course. Universidad De Puerto.

[28] Rogers, L. \& Wild, R. (1996). Data-logging: effects on practical science. Journal of Computer Assisted Learning, 12, $130-145$.

[29] Rossi-Le, L. (1995). Learning styles and strategies in adult immigrant ESL students. In J.M. Reid (ed.), Learning Styles in the ESL/EFL Classroom. Boston: Heinle and Heinle, 119-25.

[30] Sankey, M. D. (2006). A neomillennial learning approach: Helping non-traditional learners studying at a distance. The International Journal of Education and Development using Information and Communication Technology (IJEDICT), 2, 4, 8299.

[31] Schwartz, J. E., \& Beichner, R. J. (1999). Essentials of educational technology. Boston: Allyn and Bacon.

[32] Sweller, J. (1999). Instructional Design. Melbourne: ACER Press. 
[33] Vollstädt W. (2002). Zukünftige Entwicklung von Lehr- und Lernmedien: Ausgewählte Ergebnisse einer Delphi-Studie. Cornelsen Stiftung, Berlin. Papers from the Neue Medien und Schulentwicklung Symposium, 25. University of Bielefeld, February.

Abbas Pourhosein Gilakjani is a Ph.D. student of Second Language Learning (SLL) at Universiti Sains Malaysia, Malaysia. He is also a faculty member of English Translation Department at Islamic University of Lahijan, Iran. He has taught English courses for over 11 years at 3 open universities in Guilan, Iran. 